Check for updates

Cite this: RSC Adv., 2017, 7, 44552

Received 22nd July 2017

Accepted 10th September 2017

DOI: $10.1039 / c 7 r a 08085 a$

rsc.li/rsc-advances

\section{Fabrication of single Pt@Au nanowire electrodes for monitoring hydrogen peroxide released from living cells $\uparrow$}

\author{
Yong Liu, Yaoyao Zhang, Hongmei Hua and Yongxin Li (D)* \\ Single platinum covered Au nanowire electrodes (Pt@AuNWEs) were fabricated by a Cu under-potential \\ deposition (UPD)/Pt redox replacement technique using a single Au nanowire as a template, and were \\ characterized by transmission electron microscopy (TEM), electrochemical method and finite-element \\ simulation. Electrochemical experiments showed that a steady-state current could be achieved for \\ common redox species, such as ferrocene ( $\mathrm{Fc})$, ferrocenemethanol $\left(\mathrm{FCCH}_{2} \mathrm{OH}\right), \mathrm{K}_{3} \mathrm{Fe}(\mathrm{CN})_{6}$ and \\ $\mathrm{Ru}\left(\mathrm{NH}_{3}\right)_{6} \mathrm{Cl}_{3}$. The prepared single Pt@AuNWEs exhibited unusual electrocatalytic activity towards the \\ reduction of $\mathrm{H}_{2} \mathrm{O}_{2}$, and were used to fabricate a nanosensor for the detection of $\mathrm{H}_{2} \mathrm{O}_{2}$ with good \\ stability and high selectivity. The as-prepared nanosensor was applied to monitor $\mathrm{H}_{2} \mathrm{O}_{2}$ released from \\ living cells stimulated by ascorbic acid with a satisfactory performance.
}

\section{Introduction}

Reactive oxygen and nitrogen species (ROS, RNS) released from cells under high metabolism conditions play an important role in some pathogenic conditions, such as cancer development, heart failure and neurodegeneration. ${ }^{\mathbf{1 , 2}}$ To identify the changes of ROS/ RNS concentrations, such as hydrogen peroxide, which is one of the important ROS generated during the oxidative burst process, several novel electrochemical sensors have been developed..$^{3-8}$ Unfortunately, most of the previous works for monitoring hydrogen peroxide released from cells were based on macro or micro-size electrodes. This leads to limitations in detecting the release of intracellular fluid due to the large size of the probe.

Owing to their high mass-transport rate, low RC constants and the ability for measurements in highly resistive solutions, single nanoelectrodes have been widely used in fundamental electrochemistry, ${ }^{\mathbf{9 - 1 4}}$ scanning electrochemical microscopy (SECM) ${ }^{15-18}$ neurobiology and single cell research.,19-21 Recently, single Pt disk nanoelectrodes were used to monitoring ROS/RNS release in cultured human breast cells, ${ }^{22}$ but Mirkin et al. have pointed out that the polished Pt nanoelectrodes are not suitable for ROS/RNS sensing due to $\mathrm{Pt}$ passivation problem. ${ }^{5}$ To solve this issue, Mirkin and Amatore have developed a methodology for ROS/RNS sensing by depositing Pt black inside an etched nanocavity under the control of atomic force microscope. ${ }^{5}$ Schuhmann et al. have developed a Prussian

Anhui Key Laboratory of Chemo/Biosensing, College of Chemistry and Materials Science, Anhui Normal University, Wuhu, 241000, P. R. China. E-mail: yongli@mail. ahnu.edu.cn; Fax: +86-553-386-9303; Tel: +86-553-386-9302

† Electronic supplementary information (ESI) available. See DOI: 10.1039/c7ra08085a blue modified carbon nanoelectrode to detect hydrogen peroxide. ${ }^{23}$ Compared to Pt nanoelectrodes, Au nanoelectrodes have wider applications in bio-analysis, and Au nanodisk electrodes have been used to analyze bio-molecules. ${ }^{11,24}$ However, the detection sensitivity may be limited by the tiny surface area of $\mathrm{Au}$ nanodisk electrodes though the nanoelectrodes could be used for real-time analysis in living bio-system. Therefore, development of Au-based nanoelectrodes with relative larger surface area and ultra-small size is urgently important for realtime monitoring analytes in living system.

In this work, we have developed a unique methodology to fabricate single $\mathrm{Pt}$ covered $\mathrm{Au}$ nanowire electrodes (Pt@AuNWEs) by etching single Au nanodisk electrodes and a $\mathrm{Cu}$ under-potential deposition (UPD)/Pt redox replacement technique. ${ }^{25,26}$ Scheme 1 shows the process of the fabrication of single Pt@AuNWE and the reduction of hydrogen peroxide released from living cells under the stimulation of ascorbic acid. Transmission Electron Microscopy (TEM), electrochemical method and finite-element simulation were used to characterize the prepared single Pt@AuNWEs. The as-prepared single Pt@AuNWEs have demonstrated unusual electrocatalytic activity towards the reduction of $\mathrm{H}_{2} \mathrm{O}_{2}$, which have been applied to fabricate $\mathrm{H}_{2} \mathrm{O}_{2}$ sensor with high sensitivity, selectivity and stability. This hydrogen peroxide sensor has been used to monitor $\mathrm{H}_{2} \mathrm{O}_{2}$ released from living cells stimulated with ascorbic acid (AA) with satisfactory performance.

\section{Experimental section}

\subsection{Materials and reagents}

Potassium ferricyanide $\left(\mathrm{K}_{3} \mathrm{Fe}(\mathrm{CN})_{6}\right.$, AcrosOrganics $)$, hexaammineruthenium(III) chloride $\left(\mathrm{Ru}(\mathrm{NH})_{3}\right)_{6} \mathrm{Cl}_{3}$, Shanghai 


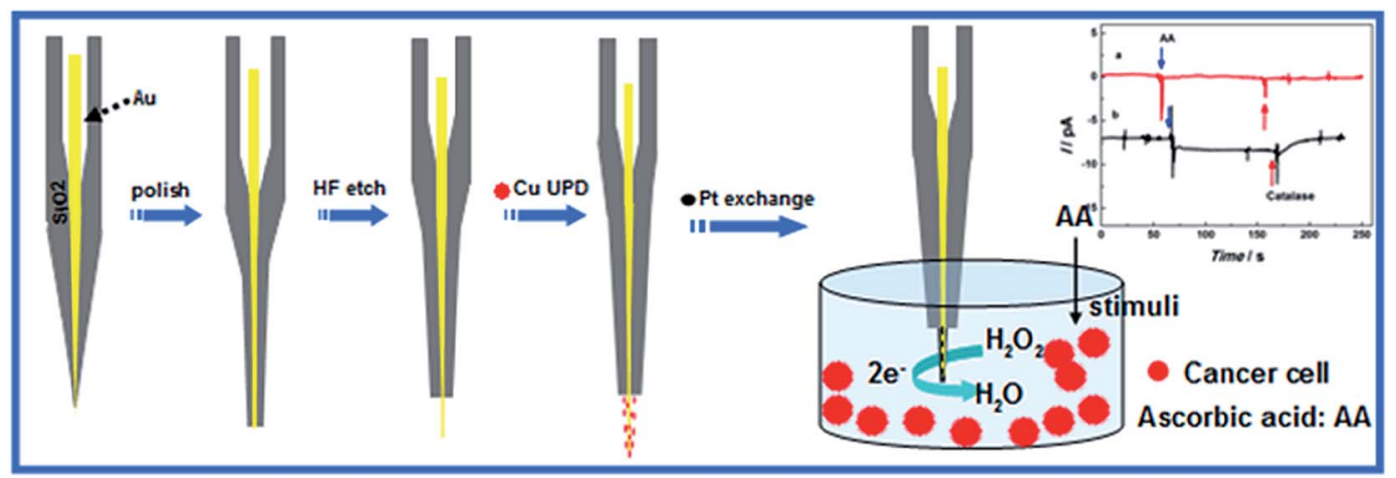

Scheme 1 Schematic diagram showing the modified etch and copper underpotential deposition (UPD) redox replacement process for the preparation of Pt@Au nanowire electrode.

Chemical Co., Shanghai, China, ferrocene (Fc, Fluka), ferrocenemethanol $\left(\mathrm{FcCH}_{2} \mathrm{OH}\right.$, Aldrich), potassium chloride (KCl, Shanghai Chemical Co., Shanghai, China), acetonitrile (ACN, Shanghai Chemical Co., Shanghai, China), tetra- $n$-butylammonium hexafluorophosphate $\left(\mathrm{TBAPF}_{6}\right.$, Aldrich), ascorbic acid (AA, Shanghai Chemical Co., Shanghai, China), uric acid (UA, Shanghai Chemical Co., Shanghai, China) and catalase (Shanghai Chemical Co., Shanghai, China) were of reagent grade or better, and used without further purification. Organic and aqueous solutions were prepared from acetonitrile and Milli-Q water, respectively. $\mathrm{K}_{2} \mathrm{PtCl}_{4} \cdot 6 \mathrm{H}_{2} \mathrm{O}(\mathrm{Pt} \%>40 \%), \mathrm{Au}$ microwires $(99.95 \%$, hard, r.d. $=25 \mu \mathrm{m})$ and $\mathrm{Cu}\left(\mathrm{NO}_{3}\right)_{2}$ were purchased from Alfa Aesar. Borosilicate glass capillaries (i.d. $\sim 0.64 \mathrm{~mm}$, o.d. $\sim 1.0 \mathrm{~mm}$ ) were purchased from Sutter Instrument Co. (Novato, CA). Fine grit sandpapers with 400, 600, and 800 grits and alumina polishing powders with different particle sizes of 1.0, 0.3, and $0.05 \mathrm{~mm}$ were obtained from Buehler (Lake Bluff, IL). A fresh solution of $\mathrm{H}_{2} \mathrm{O}_{2}$ was prepared daily.

\subsection{Instruments}

A laser-assisted puller (P-2000 mode, Sutter Instrument Co., Novato, CA) was used for the fabrication of $\mathrm{Au}$ nanowires. Electrochemical experiments were carried out using an electrochemical workstation controlled by computer (CHI 760 mode, Shanghai, China). A Ag/AgCl electrode (CHI instrument, Shanghai, China) was used as the reference electrode and a platinum wire as auxiliary electrode.

TEM images were performed on a Tecnai G2.F20 (FEI, Japan) microscope.

\subsection{Fabrication of single Pt@AuNWEs}

Before preparation of single AuNWEs and Pt@AuNWEs, single $\mathrm{Au}$ nanodisk electrodes were obtained as we previously reported ${ }^{11}$ and the radii of the single nanodisk electrodes can be calculated. ${ }^{27}$ Single Pt@AuNWEs could be fabricated through the following two steps: first, single Au nanodisk electrode was immersed into $\mathrm{HF}(1: 4, \mathrm{v} / \mathrm{v})$ solution for etching $\mathrm{SiO}_{2}$ layer and single Au nanowire could be exposed. Then, a copper underpotential deposition (UPD) redox replacement reaction was carried out on the surface of single Au nanowire ${ }^{28,29}$ through holding the potential at $\sim 0.20 \mathrm{~V}$ in a $0.1 \mathrm{M} \mathrm{HClO}_{4}+1.0 \mathrm{mM}$ $\mathrm{Cu}\left(\mathrm{NO}_{3}\right)_{2}$ solution for $2 \mathrm{~min} .{ }^{26,29}$ After that, the electrode was immersed in a freshly prepared nitrogen-purged solution of $0.10 \mathrm{M} \mathrm{H}_{2} \mathrm{SO}_{4}$ containing $5.0 \mathrm{mM} \mathrm{K}_{2} \mathrm{PtCl}_{4}$ for $\sim 15 \mathrm{~min}$ to make sure that the redox replacement between UPD $\mathrm{Cu}$ and $\mathrm{Pt}$ finished completely, and uniform Pt@Au nanowires can be obtained. The length of the single Pt@AuNWEs can be estimated from steady-state limiting current obtained from the cyclic voltammetry (CV) of redox species ${ }^{13,30}$ and also can be obtained from finite simulation results. ${ }^{31}$

\subsection{Monitoring $\mathrm{H}_{2} \mathrm{O}_{2}$ released from MCF-7 cells}

Human breast cancer cells MCF-7 provided by Wannan Medical University were used as target molecules to investigate the real applications of proposed nanosensors. MCF-7 cells were maintained in Dulbecco's modified Eagle medium (supplemented with $100 \mathrm{U} \mathrm{ml}^{-1}$ penicillin and $10 \%$ fetal bovine serum) and incubated at $37{ }^{\circ} \mathrm{C}$ in a humidified incubator $\left(5 \% \mathrm{CO}_{2}\right.$ and $95 \%$ air). ${ }^{8}$ MCF-7 cells were digested with $0.25 \%$ pancreatin for $120 \mathrm{~s}$ and then centrifuged for $10 \mathrm{~min}(1000 \mathrm{rpm})$ and washed with phosphate buffer for three times. The obtained cells were re-suspended into $5 \mathrm{ml}$ PBS. When the current reached to a steady state, ascorbic acid (AA) and catalase $\left(500 \mathrm{U} \mathrm{ml}^{-1}\right)$ was injected to the cells solution, which could motivate $\mathrm{H}_{2} \mathrm{O}_{2}$ generation and reduce $\mathrm{H}_{2} \mathrm{O}_{2}$ selectively. In control experiment, AA and catalase were added into the solution without cells at the same conditions.

\section{Results and discussion}

\subsection{Characterization and electrochemistry of single AuNWEs}

The structure and morphology of single AuNWEs were provided through TEM image (Fig. 1). From Fig. 1, a single Au nanowire with the radius of $\sim 30 \mathrm{~nm}$ and the length of $\sim 100 \mathrm{~nm}$ could be observed clearly, which was sealed with glassy sheath and the surface between $\mathrm{SiO}_{2}$ and single $\mathrm{Au}$ wire is smooth, and no obvious gap can be observed.

Steady-state voltammetry in a $5 \mathrm{mM}$ Fc solution was used to characterize the $\mathrm{Au}$ nano-disk electrodes before and after $\mathrm{HF}$ etching process, as shown in Fig. 2A. Assuming a single $\mathrm{Au}$ 


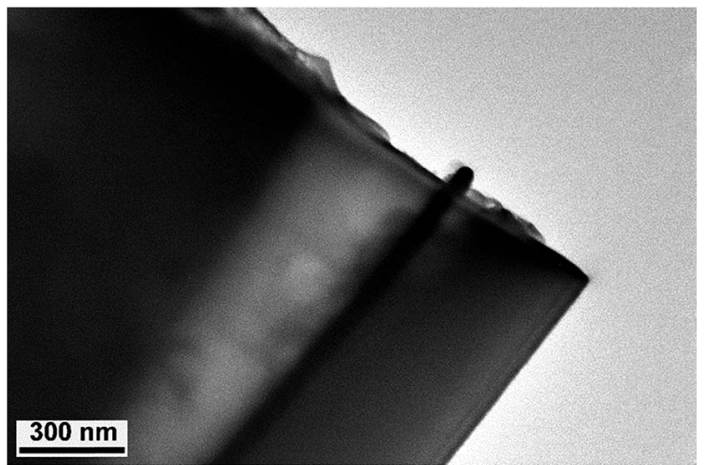

Fig. 1 TEM image of single $\mathrm{Au}$ nanowire electrode with radius of $\sim 30 \mathrm{~nm}$ and the length of $\sim 100 \mathrm{~nm}$.

nanoelectrode with disk-shaped geometry embodied in an infinitely large insulation material of $\mathrm{SiO}_{2}$, the radius of Au disk nanoelectrode can be calculated from steady-state limiting current: ${ }^{14,27}$

$$
i_{\mathrm{d}}=4 n F D C_{\mathrm{b}} a
$$

where $i_{\mathrm{d}}$ is the steady-state limiting current of Fc, $n$ is the number of electron transferred per molecule, $D$ is the diffusion coefficient, $F$ is Faraday's constant, $C_{\mathrm{b}}$ is the bulk concentration of redox species and $a$ is the radius of Au disk nanoelectrode. However, when single Au nano-disk electrode was etched by HF, the steady state current from the obtained single AuNWEs could be predicted as follows ${ }^{27,31}$

$$
i_{\mathrm{qss}}=\frac{2 n F A D C_{\mathrm{b}}}{r_{0} \operatorname{In\tau }}
$$

where $i_{\mathrm{qss}}$ is the steady state limiting current, $r_{0}$ is the radius of nanowire, $\tau=4 D t / r_{0}{ }^{2}$, and other parameters are the same as above. The time component, $t$, can be predicted as $t=\left(\frac{R T}{F v}\right)$, where $v$ is the potential scan rate.

The cyclic voltammetric scan in $\mathrm{H}_{2} \mathrm{SO}_{4}$ solution was always applied to characterize metal electrodes, especially for gold and platinum electrodes through their characteristic peaks for the formation of surface oxides and their subsequent reduction in acid electrolytes..$^{25,26,29}$ The single Au nano-disk electrode before and after $\mathrm{HF}$ etching was scanned in a $0.5 \mathrm{M}$ $\mathrm{H}_{2} \mathrm{SO}_{4}$ solution (shown in Fig. $2 \mathrm{~B}$ ). From Fig. 2B, it can be obtained that all the nanoelectrodes showed the characteristic peak of gold in $0.5 \mathrm{M} \mathrm{H}_{2} \mathrm{SO}_{4}$ neither the electrode is etched or not. During the forward sweep, it appeared the oxidation peak at around $1.4 \mathrm{~V}$. And the reduction peak was occurred at about $0.95 \mathrm{~V}$ when the potential swept to the opposite direction. The reduction peak of Au nanoelectrode after etching has a slightly shift towards negative direction. It is consistent with other literature reports. ${ }^{11,26}$

The length of the Au nanowire electrode can be estimated by the COMSOL simulation software (Fig. S1 in ESI†) through the comparison of CVs from experimental result and simulation data. ${ }^{32}$ As shown in Fig. S2 (ESI $\dagger$ ), the length of single AuNWE is $\sim 71 \mathrm{~nm}$ approximately.
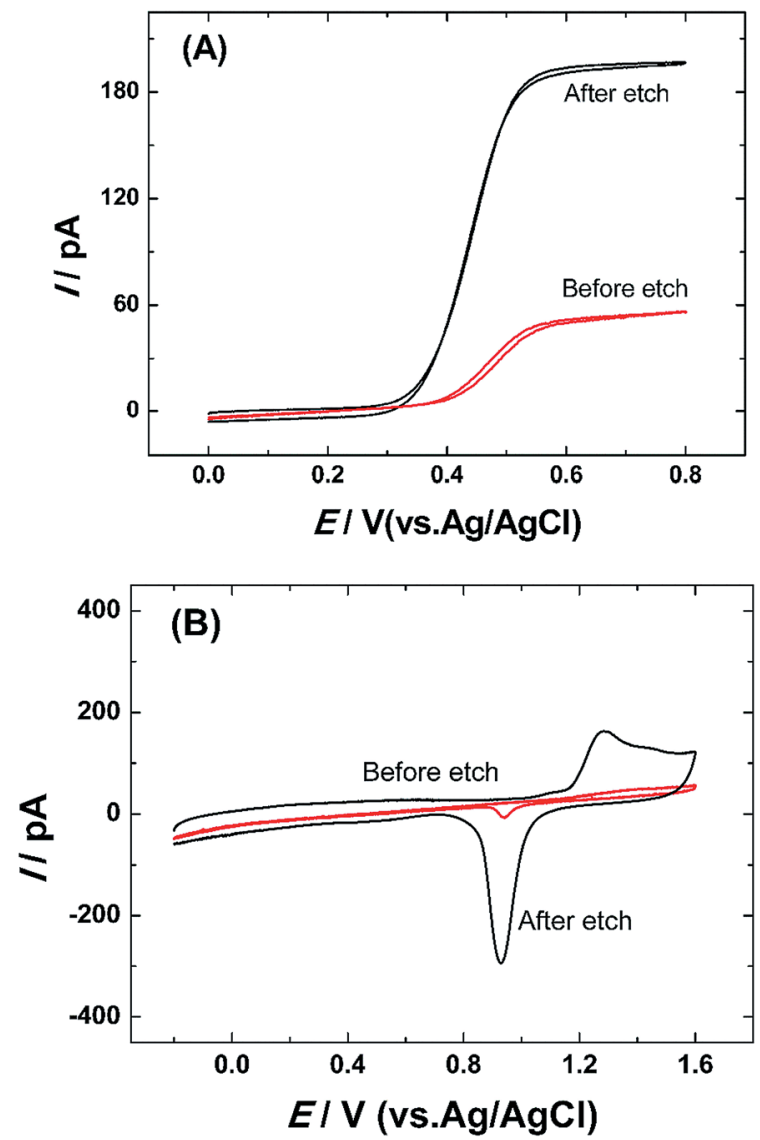

Fig. 2 Voltammetric responses of Au nanodisk electrode (red line) and $\mathrm{HF}$ etched $\mathrm{Au}$ nanodisk electrode (black line) in an $\mathrm{ACN}$ solution containing $5 \mathrm{mM} \mathrm{Fc}+0.2 \mathrm{M} \mathrm{TBAPF}_{6}(\mathrm{~A})$, and a $0.5 \mathrm{M} \mathrm{H}_{2} \mathrm{SO}_{4}$ solution (B). Scan rate: $50 \mathrm{mV} \mathrm{s}^{-1}$.

The voltammetric responses using single AuNWEs with different lengths ( $0 \mathrm{~nm}, 6 \mathrm{~nm}, 21 \mathrm{~nm}, 80 \mathrm{~nm}$ and $129 \mathrm{~nm}$ ) were recorded using four different redox species, such as $\mathrm{Fc}$, $\mathrm{FcCH}_{2} \mathrm{OH}, \mathrm{K}_{3} \mathrm{Fe}(\mathrm{CN})_{6}$, and $\mathrm{Ru}\left(\mathrm{NH}_{3}\right)_{6} \mathrm{Cl}_{3}$, and the results are given in Fig. 3. From Fig. 3, it can be observed that all the voltammograms collected from 4 different redox species were welldefined sigmoidal shape with low hysteresis phenomena between the forward and backward sweeps, indicating that the prepared single AuNWEs were prepared very well and had good steady-state responses.

\subsection{Fabrication and characterization of single Pt@Au nanowire electrodes}

Copper under-potential deposition/Pt redox replacement reaction has been taken to fabricate single Pt@AuNWEs: $:^{25,26,29}$ a monolayer of copper was deposited on the surface of single AuNWE through holding the potential at $\sim 0.2 \mathrm{~V}$ for $2 \mathrm{~min}$ in a $0.1 \mathrm{M} \mathrm{HClO}_{4}+1.0 \mathrm{mM} \mathrm{Cu}\left(\mathrm{NO}_{3}\right)_{2}$ solution. After that, the copper covered single AuNWE was put into a $0.1 \mathrm{M} \mathrm{H}_{2} \mathrm{SO}_{4}+$ 5.0 $\mathrm{M} \mathrm{K}_{2} \mathrm{PtCl}_{4}$ solution for $15 \mathrm{~min}$, and the UPD copper could be replaced by Pt completely. The copper deposition and sweep process on the surface of single AuNWE could be observed by a typical cyclic voltammogram in a $0.1 \mathrm{M} \mathrm{HClO}_{4}+1.0 \mathrm{mM}$ 

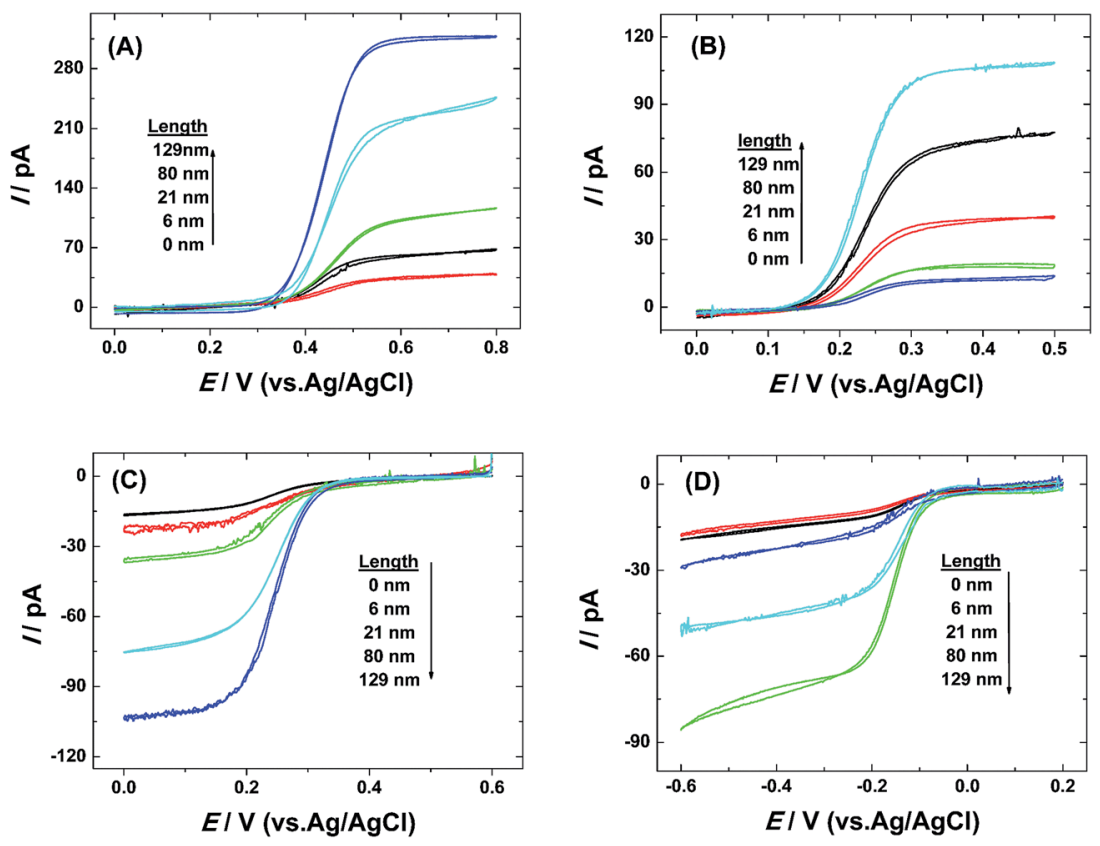

Fig. 3 Voltammetric responses of Au nanowire electrodes in a $5 \mathrm{mM} \mathrm{Fc} \mathrm{ACN}$ solution containing $0.2 \mathrm{M} \mathrm{TBAPF}_{6}(\mathrm{~A}), 1 \mathrm{mM} \mathrm{FcCH}_{2} \mathrm{OH}_{\mathrm{containing}}$ $0.1 \mathrm{M} \mathrm{KCl}(\mathrm{B}), 5 \mathrm{mM} \mathrm{K}_{3} \mathrm{Fe}(\mathrm{CN})_{6}$ containing $0.2 \mathrm{M} \mathrm{KCl}(\mathrm{C})$, and $5 \mathrm{mM} \mathrm{Ru}\left(\mathrm{NH}_{3}\right)_{6} \mathrm{Cl}_{3}$ containing $0.2 \mathrm{M} \mathrm{KCl}(\mathrm{D})$. Scan rate is $10 \mathrm{mV} \mathrm{s}^{-1}$. Radius of single Au nano-disk electrode, $\sim 9.6 \mathrm{~nm}$. Radii of single Au nanoelectrodes, $6 \mathrm{~nm}, 21 \mathrm{~nm}, 80 \mathrm{~nm}$ and $129 \mathrm{~nm}$.

$\mathrm{Cu}\left(\mathrm{NO}_{3}\right)_{2}$ solution shown in Fig. 4A, and the two pairs of cathodic/anodic peaks correspond to the formation/dissolution of UPD copper ( $a$ and $\left.a^{\prime}\right)$ and bulk copper ( $b$ and $\left.b^{\prime}\right)$.

The obtained nanowire electrode was put into a $0.5 \mathrm{M} \mathrm{H}_{2} \mathrm{SO}_{4}$ solution for cyclic voltammetric scan to confirm the formation of Pt on the surface of single AuNWE and the cyclic voltammogram was provided in Fig. 4B. From the typical hydrogen desorption-adsorption peaks at $\sim 0.1--0.2 \mathrm{~V}$ and the typical reduction peak of Pt oxide at $\sim 0.42 \mathrm{~V}$ (Fig. $4 \mathrm{~B}$, red curve), it could be obtained that UPD copper was replaced by Pt and a single Pt@AuNWE was fabricated successfully. ${ }^{25,26,29}$ Moreover, a small reduction peak at $\sim 0.91 \mathrm{~V}$ could be found in the cyclic voltammogram by use of single Pt@AuNWE (Fig. 4B, red curve), indicating that few Au sites still exposed in the solution and $\mathrm{Pt}$ shell was discontinued on the surface of single AuNWE. ${ }^{33,34}$ For comparison, the CV of single AuNWE before UPD copper deposition/Pt replacement in a $0.5 \mathrm{M} \mathrm{H}_{2} \mathrm{SO}_{4}$ solution was also provided (Fig. 4B, black curve), and the typical oxidation peaks at $\sim 1.4 \mathrm{~V}$ and reduction peak at $\sim 0.95 \mathrm{~V}$ proved the bare AuNWE existing in the solution.

\subsection{Electrocatalytic reduction of hydrogen peroxide at single Pt@AuNWEs}

The electrocatalytic activity of prepared single Pt@AuNWEs towards the reduction of $\mathrm{H}_{2} \mathrm{O}_{2}$ was investigated by cyclic voltammetry. Fig. 5A shows the typical CVs of $0.5 \mathrm{mM} \mathrm{H}_{2} \mathrm{O}_{2}$ in a $10 \mathrm{mM}$ PBS ( $\mathrm{pH}=7.4$ ) by use of single Pt@AuNWEs with different lengths. From Fig. 5A, it could be observed that the cyclic voltammograms of $\mathrm{H}_{2} \mathrm{O}_{2}$ reduction showed well-defined steady state current with obvious steep gradient. However, the CVs collected from single Pt nanowire electrode (Fig. 5B) and single Au nanowire electrode (Fig. 5C) did not show steady state current, and the shape was poor without gradient. Moreover, the output current obtained from single Pt@AuNWE is much larger than that from single Pt nanowire electrode and single $\mathrm{Au}$ nanowire electrode when the length of all of the electrodes is $\sim 200 \mathrm{~nm}$. These results demonstrate that the $\mathrm{H}_{2} \mathrm{O}_{2}$ electroreduction using single Pt@AUNWEs has a diffusion-controlled process $^{27}$ and faster electron transfer rate, and single Pt@AuNWEs can be used to fabricate nanosensor for $\mathrm{H}_{2} \mathrm{O}_{2}$ sensing.

For amperometric detection of $\mathrm{H}_{2} \mathrm{O}_{2}$, the reduction potential is key parameter to achieve high sensitivity. ${ }^{3}$ Fig. S3 (ESI $\dagger$ ) shows the amperometric responses of the single Pt@AuNWE to the successive additions of $4 \mu \mathrm{M} \mathrm{H}_{2} \mathrm{O}_{2}$ into $10 \mathrm{mM}$ the stirring $\mathrm{PBS}(\mathrm{pH}=7.4)$ at the applied potential of $0.1 \mathrm{~V}$ (black curve), $0.15 \mathrm{~V}$ (red curve), $0.25 \mathrm{~V}$ (green curve), respectively. From Fig. S3 (ESI $\dagger$ ), it could be obtained that the amperometric response using single Pt@AuNWE at the applied potential of $0.25 \mathrm{~V}$ had a gradual slope, but steep slopes could be found at the applied potential of $0.1 \mathrm{~V}$ and $0.15 \mathrm{~V}$, indicating $\mathrm{H}_{2} \mathrm{O}_{2}$ reduction should have high sensitivity and fast response. Although more negative potential should have good sensitivity, the interferences species, such as ascorbic acid and uric acid, would cause big concern for hydrogen peroxide detection. Therefore, $0.10 \mathrm{~V}$ was chosen for amperometric detection of $\mathrm{H}_{2} \mathrm{O}_{2}$.

Fig. 6A provides the typical steady-state amperometric response of single Pt@AuNWE (black curve) to successive injection of $4 \mu \mathrm{M} \mathrm{H}_{2} \mathrm{O}_{2}$ into stirring PBS solution at the applied potential of $0.10 \mathrm{~V}$, thus no obvious steady-state current could be found by use of single AuNWE (red curve) at the same test 

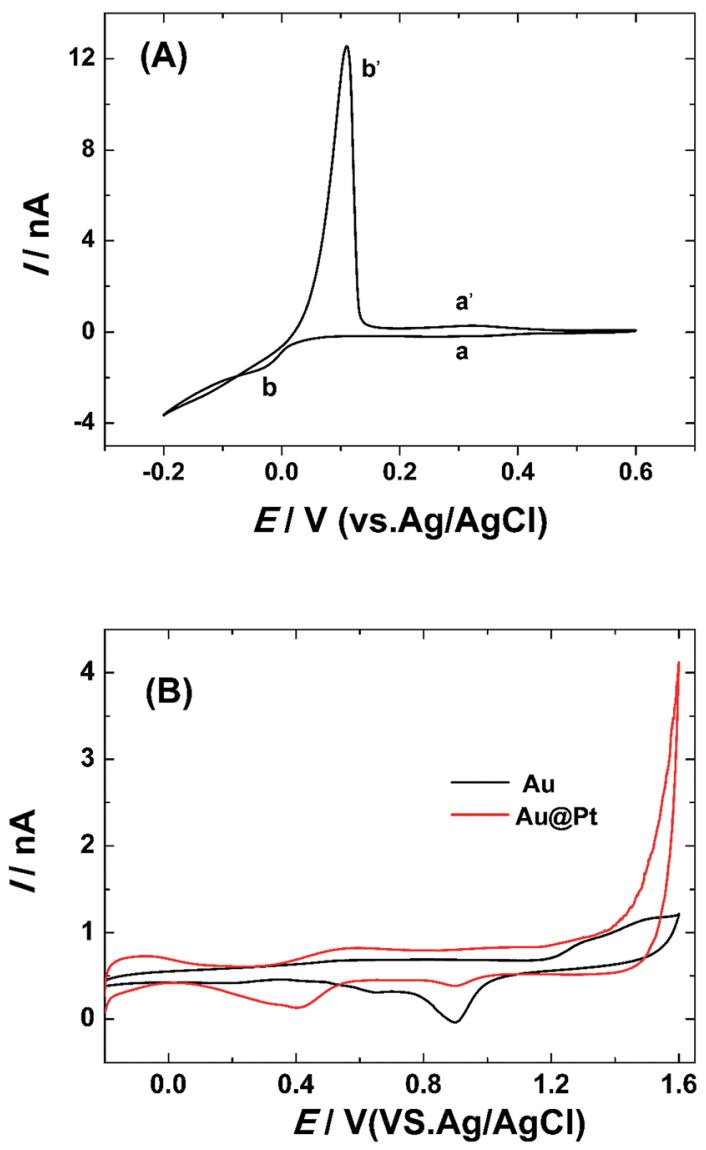

Fig. 4 (A) $\mathrm{CV}$ of single AuNWE in a $0.1 \mathrm{M} \mathrm{HClO}_{4}$ solution containing $1 \mathrm{mM} \mathrm{Cu}\left(\mathrm{NO}_{3}\right)_{2}$. Scan rate, $50 \mathrm{mV} \mathrm{s}^{-1}$. (B) CVs of single AuNWE (black curve) and Pt@AuNWE (red curve) in a $0.5 \mathrm{M} \mathrm{H}_{2} \mathrm{SO}_{4}$ solution. Scan rate, $50 \mathrm{mV} \mathrm{s}^{-1}$; radius, $\sim 10 \mathrm{~nm}$; length, $\sim 200 \mathrm{~nm}$. conditions. The single Pt@AuNWE could achieve 95\% in its steady state current within $5 \mathrm{~s}$, indicating fast electron transfer rate and rapid diffusion of hydrogen peroxide on the surface of the electrode. The linear relationship between the increasing current and the concentration of $\mathrm{H}_{2} \mathrm{O}_{2}$ at the range of 0.15$3.2 \mu \mathrm{M}$ could be obtained (shown in Fig. 6B) according to the amperometric response, and the linear regression equation was $I(\mathrm{pA})=-2.444-6.184 C(\mu \mathrm{M})\left(R^{2}=0.9942\right)$. Based on IUPAC rules, ${ }^{35}$ the limit of detection (LOD) can be defined as: $\mathrm{LOD}=$ $3.29 \sigma_{\text {blank }} / S$, where $S$ is the slope of the linear calibration plot, which indicating the method calibration sensitivity, and $\sigma_{\text {blank }}$ is the blank standard deviation. Using the above equation, the LOD of $\mathrm{H}_{2} \mathrm{O}_{2}$ could be calculated to be $0.12 \mu \mathrm{M}$. Under the optimum conditions, the relative standard deviation (R.S.D.) for nine successive determinations of $2.0 \mu \mathrm{M} \mathrm{H} \mathrm{H}_{2} \mathrm{O}_{2}$ was $2.27 \%$, indicating the excellent reproducibility of the present system. According to regulations by IUPAC, ${ }^{36}$ the regression model diagnosis has been considered satisfactory with no lack of fit because the value of $F_{\text {calculated }}(1.74)$ is lower than $F_{\text {critical }}$ (3.18) within a $95 \%$ confidence interval, indicating that the linearity test was considered acceptable in the concentration range. Although similar results have been obtained from micro/macro electrodes, ${ }^{3,23,25}$ considering the tiny dimension and faster mass transport rate, the proposed nanosensor has significant advantage for sensing application in living-system.

The stability and selectivity of the prepared single Pt@AuNWE-based nanosensor were also investigated, as shown in Fig. S4 and S5 (ESI $\dagger$ ). The stability of the nanoelectrode was tested by amperometric detection in the injection of $10 \mu \mathrm{M}$ $\mathrm{H}_{2} \mathrm{O}_{2}$ periodically at days 1 , day 3 and day 5, respectively (Fig. S4, ESI $\dagger$ ). The single Pt@AuNWE was put into a $10 \mathrm{mM}$ PBS
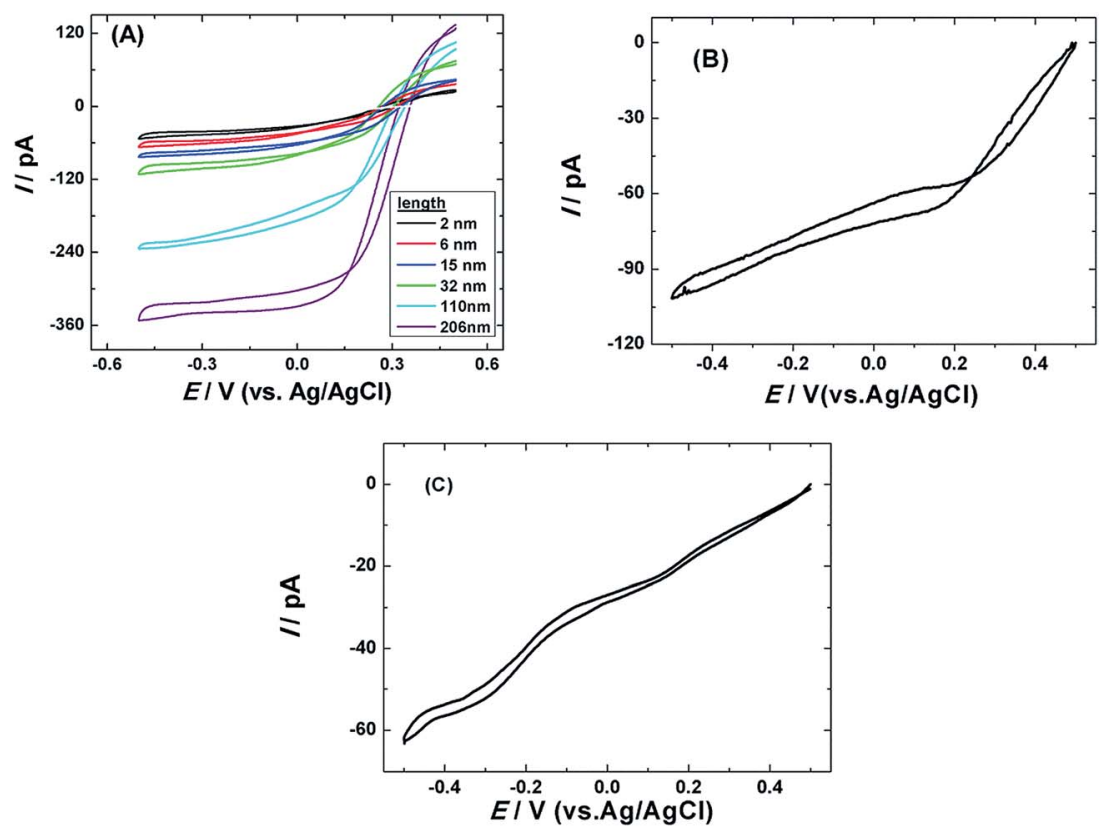

Fig. $5 \mathrm{CVs}$ of $10 \mathrm{mM}$ PBS ( $\mathrm{pH}$ 7.4) containing $0.5 \mathrm{mM} \mathrm{H}_{2} \mathrm{O}_{2}$ by use of single Pt@AuNWEs with the length of $2 \mathrm{~nm}$ (black), $6 \mathrm{~nm}$ (red), $15 \mathrm{~nm}$ (blue), $32 \mathrm{~nm}$ (green), $110 \mathrm{~nm}$ (cyan) and $206 \mathrm{~nm}$ (purple) (A), single Pt nanowire electrode with the length of $192 \mathrm{~nm}$ (B), and single Au nanowire electrode with the length of $\sim 200 \mathrm{~nm}$ (C). Radii, $5 \mathrm{~nm}$; scan rate, $10 \mathrm{mV} \mathrm{s}^{-1}$. 

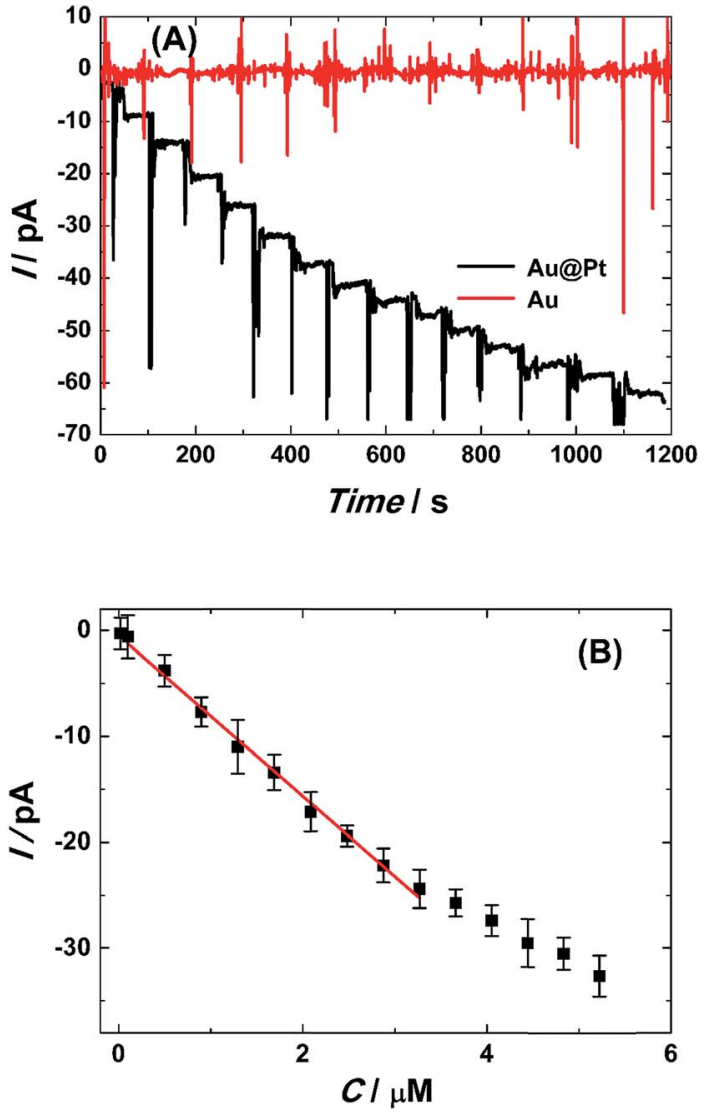

Fig. 6 (A) The typical steady-state amperometric responses to successive injection of $4 \mu \mathrm{M} \mathrm{H}_{2} \mathrm{O}_{2}$ into stirring $10 \mathrm{mM}$ PBS solution at the applied potential of $0.10 \mathrm{~V}$ by use of single Pt@AuNWE (black curve) and single AuNWE (red curve). (B) Plots of chronoamperometry currents vs. $\mathrm{H}_{2} \mathrm{O}_{2}$ concentrations collected from single Pt@AuNWE from $0.15 \mu \mathrm{M}$ to $3.2 \mu \mathrm{M}$. Applied potential, $0.10 \mathrm{~V}$; radius of the nanoelectrode, $\sim 10 \mathrm{~nm}$; length of the nanoelectrode, $\sim 200 \mathrm{~nm}$.

solution ( $\mathrm{pH}$ 7.4) for storage after each detection. It can be seen that the decrease of current value is only $2.2 \%$ and $2.7 \%$ in the three and five days respectively. For the selective study, we investigated the amperometric responses of common interference species co-existing in biological system upon consecutive addition of $10 \mu \mathrm{M} \mathrm{H}_{2} \mathrm{O}_{2}, 0.5 \mathrm{mM}$ ascorbic acid (1), $0.1 \mathrm{mM}$ dopamine (2), $1.0 \mathrm{mM}$ glucose (3), $1.0 \mathrm{mM}$ uric acid (4), $1.0 \mathrm{mM}$ lysine (5), and 1.0 mM L-cysteine (6) (shown in Fig. S5, ESI†े). The results showed that the amperometric current changed greatly after the injection of $\mathrm{H}_{2} \mathrm{O}_{2}$, while no obvious amperometric current change could be found after the injections of common interference species, indicating that these species do not interference with the detection of $\mathrm{H}_{2} \mathrm{O}_{2}$. Therefore, the good stability, high selectivity and fast response showed that the single Pt@AuNWE-based nanosensor could be utilized for dynamic monitoring hydrogen peroxide, which overcome the Pt passivation problem.

\subsection{Monitoring $\mathrm{H}_{2} \mathrm{O}_{2}$ released from living cells}

To investigate the application of single Pt@AuNWE for the detection of the dynamic release of hydrogen peroxide from

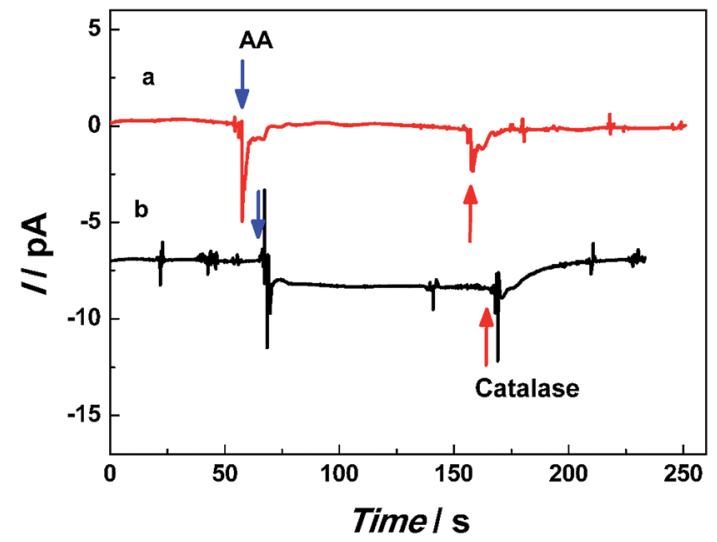

Fig. 7 Amperometric responses by use of single Pt@AuNWE in a $10 \mathrm{mM}$ PBS solution ( $\mathrm{pH}$ 7.4) with the presence (black curve) and absence (red curve) of MCF-7 cells at the applied potential of $0.10 \mathrm{~V}$ (vs. $\mathrm{Ag} / \mathrm{AgCl}$ ) upon successive addition of $1.0 \mathrm{mM} \mathrm{AA}$ and $500 \mathrm{U} \mathrm{ml}^{-1}$ catalase.

cells, MCF-7 cells were chosen as model cells and ascorbic acid was chosen as stimulator which could induce the generation of $\mathrm{H}_{2} \mathrm{O}_{2}$ from cells. Fig. 7 gives the amperometric responses by use of single Pt@AuNWE in a $10 \mathrm{mM}$ PBS solution (pH 7.4) with the presence (black curve) and absence (red curve) of MCF-7 cells at the applied potential of $0.10 \mathrm{~V}(v s . \mathrm{Ag} / \mathrm{AgCl})$ upon successive addition of $1.0 \mathrm{mM} \mathrm{AA}$ and $500 \mathrm{U} \mathrm{ml}^{-1}$ catalase. From the black curve in Fig. 7, it could be observed that the cathodic current was increased sharply after the addition of AA into PBS solution containing MCF-7 cells, which then reached a steady state within several seconds, indicating that the $\mathrm{H}_{2} \mathrm{O}_{2}$ was released stably from MCF-7 cells at the stimulation of AA. ${ }^{8}$ To identify the increased current was from $\mathrm{H}_{2} \mathrm{O}_{2}$ released from cells, a $500 \mathrm{U} \mathrm{ml}^{-1}$ catalase was injected into the test solution. It could be found from black curve in Fig. 7 that the steady state current decreased quickly, and almost went back to background line after $\sim 10$ seconds, indicating the released $\mathrm{H}_{2} \mathrm{O}_{2}$ was decomposed into water and oxygen at the existing of catalase, and the nanosensor would consume the produced oxygen. Therefore, it could be observed that the cathodic current decreased down to background line for several seconds and the cathodic current is produced from $\mathrm{H}_{2} \mathrm{O}_{2}$ released from living cells. Based on the current change from Fig. 7, the concentration of released $\mathrm{H}_{2} \mathrm{O}_{2}$ could be calculated as $\sim 0.15 \mu \mathrm{M}$ according to the regression equation listed above. For control experiment, no significant current change could be observed when AA and catalase were successively injected into PBS buffer without MCF-7 cells. Although above data were obtained from an aqueous solution, these results demonstrated that the prepared single Pt@AuNWEs could be utilized effectively for real-time monitoring $\mathrm{H}_{2} \mathrm{O}_{2}$ released from living cells.

\section{Conclusions}

In summary, we have fabricated single Pt@AuNWEs by Cu UPD/ Pt redox replacement technique using single AuNWEs as templates, which shows steady-state current responses to 
several redox species such as such as ferrocene $(\mathrm{Fc})$, ferrocenemethanol $\left(\mathrm{FcCH}_{2} \mathrm{OH}\right), \mathrm{K}_{3} \mathrm{Fe}(\mathrm{CN})_{6}$ and $\mathrm{Ru}\left(\mathrm{NH}_{3}\right)_{6} \mathrm{Cl}_{3}$. The asprepared single Pt@AuNWEs has been used as a nanosensor for the monitoring $\mathrm{H}_{2} \mathrm{O}_{2}$ released from living cells due to its ultra-small size, high selectivity and sensitivity. We believe this nanosensor will offer a new and facile method for real-time monitoring $\mathrm{H}_{2} \mathrm{O}_{2}$ or other analytes in living bio-system, and should be potentially applied in physiological and pathological research.

\section{Conflicts of interest}

There are no conflicts to declare.

\section{Acknowledgements}

We thank Prof. Bo Zhang (University of Washington) for his useful suggestions and discussion. This work is financially supported by the National Natural Science Foundation of China (No. 21375002; No. 21775003) and the Foundation for Innovation Team of Bioanalytical Chemistry of Anhui Province.

\section{References}

1 G. Waris and H. Ahsan, J. Carcinog., 2006, 5, 14.

2 C. Bogdan, M. Rollinghoff and A. Diefenbach, Curr. Opin. Immunol., 2000, 12, 64-76.

3 C. Xiao, Y.-L. Liu, J.-Q. Xu, S.-W. Lv, S. Guo and W.-H. Huang, Analyst, 2015, 140, 3753-3758.

4 S. Isik and W. Schuhmann, Angew. Chem., Int. Ed., 2006, 45, 7451-7454.

5 Y. Wang, J.-M. Noel, J. Velmurugan, W. Nogala, M. V. Mirkin, C. Lu, M. G. Collignon, F. Lemaitre and C. Amatore, Proc. Natl. Acad. Sci. U. S. A., 2012, 109, 11534-11539.

6 B. Reuillard, S. Gentil, M. Carriere, A. Le Goff and S. Cosnier, Chem. Sci., 2015, 6, 5139-5143.

7 X. Liu, M. Zhang, T. Xiao, J. Hao, R. Li and L. Mao, Anal. Chem., 2016, 88, 7238-7244.

8 W. Qiu, M. Xu, R. Li, X. Liu and M. Zhang, Anal. Chem., 2016, 88, 1117-1122.

9 M. V. Mirkin, T. Sun, Y. Yu and M. Zhou, Acc. Chem. Res., 2016, 49, 2328-2335.

10 Y. Y. T. Sun and M. V. Mirkin, Anal. Chem., 2016, 88, 1175811766.

11 Y. Zhang, S. Xu, Y. Qian, X. Yang and Y. Li, $R S C A d v .$, 2015, 5, 77248-77254.

12 S. Chen and Y. Liu, Phys. Chem. Chem. Phys., 2014, 16, 635652.

13 K. Dawson, A. Wahl, R. Murphy and A. O'Riordan, J. Phys. Chem. C, 2012, 116, 14665-14673.

14 Y. Li, D. Bergman and B. Zhang, Anal. Chem., 2009, 81, 54965502.

15 Y. Takahashi, A. I. Shevchuk, P. Novak, B. Babakinejad, J. Macpherson, P. R. Unwin, H. Shiku, J. Gorelik,
D. Klenerman, Y. E. Korchev and T. Matsue, Proc. Natl. Acad. Sci. U. S. A., 2012, 109, 11540-11545.

16 M. Etienne, E. C. Anderson, S. R. Evans, W. Schuhmann and I. Fritsch, Anal. Chem., 2006, 78, 7317-7324.

17 J. Clausmeyer and W. Schuhmann, TrAC, Trends Anal. Chem., 2016, 79, 46-59.

18 T. Sun, Y. Yu, B. J. Zacher and M. V. Mirkin, Angew. Chem., Int. Ed., 2014, 53, 14120-14123.

19 P. Actis, S. Tokar, J. Clausmeyer, B. Babakinejad, S. Mikhaleva, R. Cornut, Y. Takahashi, A. L. Cordoba, P. Novak, A. I. Shevchuck, J. A. Dougan, S. G. Kazarian, P. V. Gorelkin, A. S. Erofeev, I. V. Yaminsky, P. R. Unwin, W. Schuhmann, D. Klenerman, D. A. Rusakov, E. V. Sviderskaya and Y. E. Korchev, ACS Nano, 2014, 8, 875-884.

20 M. Marquitan, J. Clausmeyer, P. Actis, A. L. Cordoba, Y. Korchev, M. D. Mark, S. Herlitze and W. Schuhmann, ChemElectroChem, 2016, 3, 2125-2129.

21 Y. Liu, M. Li, F. Zhang, A. Zhu and G. Shi, Anal. Chem., 2015, 87, 5531-5538.

22 P. Sun, F. O. Laforge, T. P. Abeyweera, S. A. Rotenberg, J. Carpino and M. V. Mirkin, Proc. Natl. Acad. Sci. U. S. A., 2008, 105, 443-448.

23 J. Clausmeyer, P. Actis, A. L. Cordoba, Y. Korchev and W. Schuhmann, Electrochem. Commun., 2014, 40, 28-30.

24 S. E. Salamifar and R. Y. Lai, Anal. Chem., 2014, 86, 28492852.

25 Q. Q. Wu, Y. X. Li, H. Y. Xian, C. D. Xu, L. Wang and Z. B. Chen, Nanotechnology, 2013, 24, 025501.

26 D. Zhan, J. Velmurugan and M. V. Mirkin, J. Am. Chem. Soc., 2009, 131, 14756-14760.

27 A. J. Bard and L. R. Faulkner, Electrochemical Methods: Fundamentals and Applications, John Wiley and Sons Publishers, 2001.

28 Y. X. Li, Q. F. Lu, S. N. Wu, L. Wang and X. M. Shi, Biosens. Bioelectron., 2013, 41, 576-581.

29 Y. Li, J. T. Cox and B. Zhang, J. Am. Chem. Soc., 2010, 132, 3047-3054.

30 S. J. Percival and B. Zhang, J. Phys. Chem. C, 2013, 117, 13928-13935.

31 Y. X. Li, Q. Q. Wu, S. F. Jiao, C. D. Xu and L. Wang, Anal. Chem., 2013, 85, 4135-4140.

32 Y. Zhang, S. Xu, X. Xiao, Y. Liu, Y. Qian and Y. Li, Chem. Commun., 2017, 53, 2850-2853.

33 N. Kristian, Y. Yan and X. Wang, Chem. Commun., 2008, 353355.

34 X. Cui, S. Wu, S. Jungwirth, Z. Chen, Z. Wang, L. Wang and Y. Li, Nanotechnology, 2013, 24, 295402.

35 L. A. Currie, Pure Appl. Chem., 1995, 67, 1699-1723.

36 K. Danzer and L. A. Currie, Pure Appl. Chem., 1998, 70, 9931014. 